\title{
PHOTOCHEMICAL IMAGE FORMATION PROCESS FOR HIGH DENSITY PRINTED CIRCUIT PATTERNS
}

\author{
KATSUHIRO TAKAHASHI, KUNIHIRO IKARI, JIRO KANO and TSUTOMU TAKAMURA \\ Toshiba Research and Development Center, Kanagawa, 210, Japan
}

TOSHIHIRO UEKI, TSUGUO YAMAOKA and TAKAHIRO TSUNODA

Faculty of Engineering, Chiba University, Chiba, 280, Japan

\begin{abstract}
A new method for fabricating high density printed circuit boards has been investigated. The procedure used for photoselective metal deposition on the substrate consists of five steps: adhesion treatment, sensitization, nucleation, fog inhibition and electroless metal deposition. An adhesive coated substrate was sensitized by introducing an aqueous solution containıng anthraquinone sulfonic acid sodium salts, reducible noble metal salts and alcohol. The sensitized substrate was then exposed through a mask to a u.v. light. The noble metal nuclei produced by exposure were developed by electroless copper deposition after rinsing with aqueous solutions containing complex agents. Electrically-conductive patterns thus obtained can be further intensified by second electroless plate making.
\end{abstract}

\section{INTRODUCTION}

In the electronic industry there is a continuous growth of active devices (integrated circuits and LSI chips) but the cost of their interconnections is not being reduced correspondingly. The high densities of conductors required by modern devices usually increase rather than reduce the cost of their interconnections as long as conventional methods are used.

Techniques for selective metallization for printed circuit substrates, additive process, are able to produce high density conductors without undue cost penalty. Generally, additive technology has furnished an opportunity to use new methods for making conductive patterns and for use of non-conventional substrates instead of copper clad laminates.

Photochemical methods for manufacturing Resistless Fully Additive Circuitry are capable of resolving fine line conductors on substrates with reliable plated thru-hole interconnection. A number of approaches may be found described in pertinent literature. ${ }^{1-4}$ However, these methods have some disadvantages in regard to the conductive pattern adhesion to the substrate and the plated thru-hole interconnection reliability. Another important disadvantage is extraneous copper particles deposition in unexposed areas.
A new method was investigated for manufacturing printed circuit boards (PCB) utilizing photochemical reaction which eliminates the disadvantages in the prior method.

Photochemical reactions of anthraquinone sulfonic acid sodium salts are well known. ${ }^{5,6}$ Certain metal salts are easily reduced to their metal atoms when exposed to u.v. light in the presence of anthraquinone sulfonic acid or its alkali metal salts. ${ }^{7-9}$ Using this process, circuit patterns are made photochemically on insulating substrates coated with photosensitive materials. Then, the desired conductor pattern is formed by using electroless copper plating.

This result suggested a new method for forming an electrically conductive fine pattern on substrates without using various resists.

\section{INVESTIGATION}

The investigation has made progress on the following points.

1) Research on a highly sensitive photo-redox system using anthraquinone as a u.v. sensitizer.

2) Establishment of developing and antifogging to obtain fine lines. 
3) Improving adhesive strength between substrate and conductor pattern, and solderability.

\subsection{Materials}

Anthraquinone-2.6-disulfonic acid disodium salts (AQS) was selected as a u.v. photosensitizer. AQS was dissolved in aqueous solution comprising reducible metal salts, hydrogen donors (R-H) and wetting agent. This solution was preserved in a polyethylene bottle in a refrigerator.

\subsection{Photoreaction}

The u.v. spectra were obtained with a Hitachi spectrophotometer model EPS-3T. The amount of reduced metal was determined by centrifuge action and analyzed. The sensitizing, antifogging and developing effects were examined on the adhesive coated substrates using a Sakura Photodensitometer Model PDA-60. The irradiation source employed was a 1000W high pressure mercury lamp (ORC Co.). The sensitizing solution dark reaction was examined in an oven.

\subsection{Circuit Board Manufacturing}

The PCB manufacturing sequence is given below.

a) Substrate: Adhesive coated epoxy-paper laminates were used for the substrate. The laminates were coated with oxidizable resin containing dispersed rubber, phenolic and epoxy resin.

b) Adhesion treatment: The substrate was treated with a chemical oxidizing solution containing $\mathrm{CrO}_{3}$, $\mathrm{H}_{2} \mathrm{SO}_{4}$ and $\mathrm{H}_{2} \mathrm{O}$. This solution attacks the adhesive so as to produce a microporous, hydrophilic polar surface.

c) Photosensitization and drying: The etched substrate was immersed in a sensitizing solution and dried. A photosensitive layer was formed on the surface and in the holes of the panel. d) Exposure: The required conductor and hole image was formed by exposing the sensitized panels to u.v. light using a negative pattern. The metallic nuclei acted as catalytic sites for electroless copper deposition. The irradiation source employed was a $6000 \mathrm{~W}$ high pressure mercury lamp (ORC Co. Model HMW-236).

e) Fixation: The unexposed photosensitizer on the panel was removed in a fixing solution comprising complex agent for metal ions.

f) Metallization: The exposed regions were metallized by using a well controlled electroless copper plating solution.

\section{INTERPRETATION}

\subsection{Materials and Photoreaction}

The photographic sensitivity of the systems containing various reducible metal salts and AQS was measured by exposing the sensitized substrate through a sensitometric wedge to u.v. light. Value for $\mathrm{Em}$, the minimum exposure energy needed to initiate electroless deposition, is given in Table I. $\mathrm{PdCl}_{2}$-AQS system was more sensitive than other metal salts-AQS systems. The $\mathrm{AgNo}_{3}$-AQS system sensitivity was comparable to $\mathrm{PdCl}_{2}$-AQS system sensitivity. However, in this system, the dark reaction was observed at room temperature. In the case of nickel, copper and gold salts, a large quantity of the nuclei was required to initiate electroless deposition.

In Figure 1 the rate of reduction as a function of exposure-time is plotted for a solution containing cupric formate, AQS and various $\mathrm{R}-\mathrm{H}$ additives. Optimum concentrations of the $\mathrm{R}-\mathrm{H}$ additives were not determined. It was found that pentaerythritol (PET) markedly increased the copper nuclei formation rate (Figure 1, curve e). However, the relation between $\mathrm{R}-\mathrm{H}$ molecular structure and the copper ions reduction rate is not easy to judge from these results alone.

TABLE I

AQS-metal salts system photographic sensitivity.

\begin{tabular}{lllcc}
\hline Metal salts $\left(5.6 \times 10^{-1} \mathrm{~mol} / \mathrm{lit}\right)^{a}$ & Nuclei & Development & Em $\left(\mathrm{mJ} / \mathrm{Cm}^{2}\right)$ & $\lambda(\mathrm{nm})$ \\
\hline Cupric formate & $\mathrm{Cu}$ & Cuposit copper & $100-200$ \\
Nickel sulfate & $\mathrm{Ni}$ & mix 328 & $100-200$ & 365 \\
Palladium chloride & $\mathrm{Pd}$ & $\left(2\right.$ min, at $\left.25^{\circ} \mathrm{C}\right)$ & $1-5$ & $3-10$ \\
Silver nitrate & $\mathrm{Ag}$ & & $100-200$ & \\
Gold trichloride acid & $\mathrm{Au}$ & & & \\
\hline
\end{tabular}

${ }^{a}$ Metal salts were added to a solution containing $2.4 \times 10^{-2} \mathrm{~mol} / \mathrm{lit} \mathrm{AQS}$ and $5.5 \times 10^{-2} \mathrm{~mol} / \mathrm{lit}$ sorbitol.

${ }^{b}$ Electroless copper deposition solution was supplied by Shipley Company Inc. 


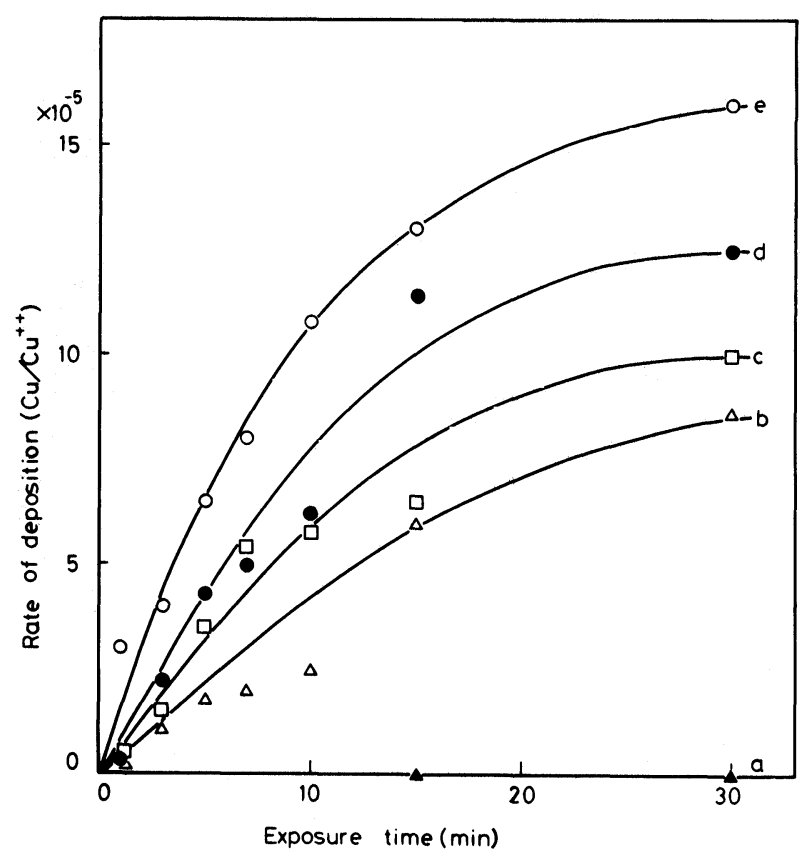

FIGURE 1 R-H additives $\left(5.5 \times 10^{-2} \mathrm{~mol} /\right.$ litre $)$ to a solution, containing $2.2 \times 10^{-1} \mathrm{~mol} /$ litre cupric formate, $2.4 \times 10^{-2} \mathrm{~mol} / \mathrm{litre} \mathrm{AQS}$, effect on the metal deposition relative rate.

a) No additive; b) Methanol; c) Isopropanol; d) Glycerin;

e) Pentaerythritol.

$\mathrm{PdCl}_{2}-\mathrm{AQS}$ system characteristic curves are shown in Figure 2. The sensitivity of the coated sensitizer containing PET was relatively low (Figure 2, curve a). The coated PET film homogeneity was inferior to that of other R-H additives. Therefore, it seems likely that the palladium ions reduction rate on the substrate was low.

Based on these results, the $\mathrm{PdCl}_{2}$-AQS-Glycerin system can be adopted as photosensitive material for circuit board manufacturing.

\subsection{Circuit Board Manufacturing}

The procedure used for photoselective metal deposition on the substrate consisted of five steps: adhesion treatment, sensitization, nucleation, fog inhibition and electroless deposition.

The surface of the substrates was cleaned and roughened. These procedures were required to obtain good adhesion between substrates and metal deposit layer. The etched substrate was sensitized by introducing a solution containing $\mathrm{PdCl}_{2}, \mathrm{AQS}, \mathrm{R}-\mathrm{H}$ and wetting agent onto its surface. For this purpose, the

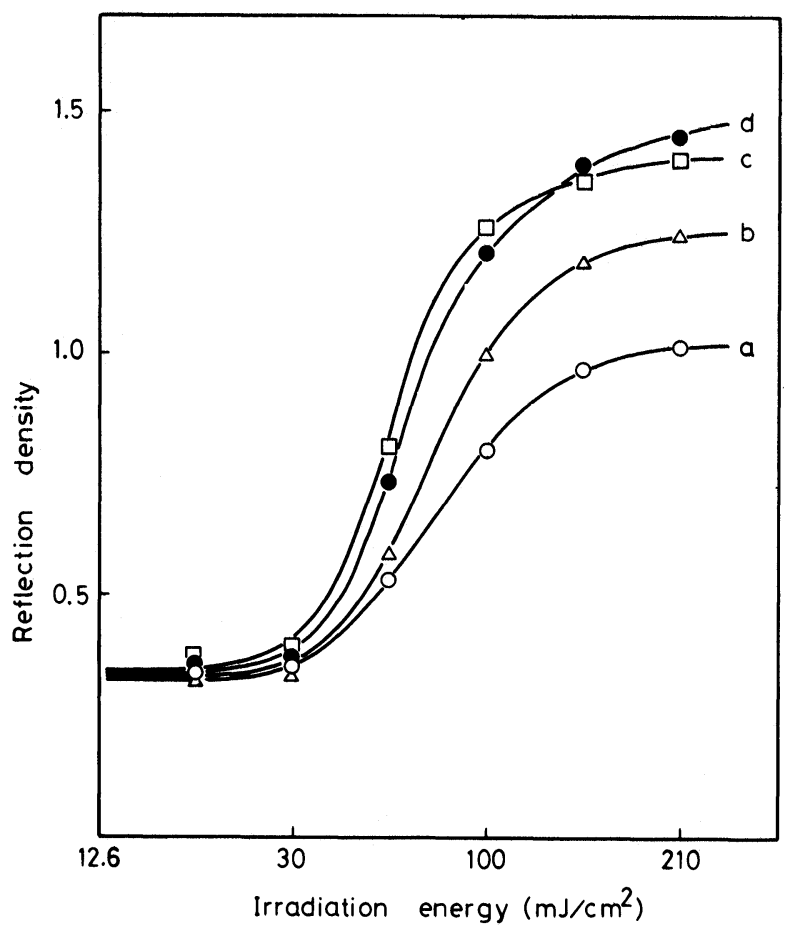

FIGURE 2 R-H additives $\left(5.5 \times 10^{-2} \mathrm{~mol} /\right.$ litre $)$ to a solution, containing $5.6 \times 10^{-1} \mathrm{~mol} /$ litre) $\mathrm{PdCl}_{2}, 1.2 \times 10^{-1}$ $\mathrm{mol} /$ litre $\mathrm{HCl}, 2.4 \times 10^{-2} \mathrm{~mol} /$ litre AQS, influence on characteristic curves.

a) Pentaerythritol; b) Methanol; c) Glycerin; d) Isopropanol.

substrate was lifted from a sensitizing solution at a controlled rate and dried superficially with warm air during lifting. An X-ray fluorescence study showed that a sensitized layer contained $0.5 \sim 1.5 \mu \mathrm{g} \mathrm{Pd} / \mathrm{cm}^{2}$ after sensitizing.

The sensitized substrate was then exposed through a mask to u.v. light. In exposed areas, the surface became activated due to the nuclei formation. In unexposed areas, palladium ions remained on the substrate surface, even after thorough rinsing with water. The presence of palladium salt caused fogging during electroless plating, since bivalent palladium could be reduced by the electroless solution reducing agent, giving rise to nucleation centers. Solution containing complex agents for bivalent palladium were effective in drastically reducing the amount of adsorbed metal salt. Satisfactory results had been obtained with aminoacetic acid and triethanolamine.${ }^{10}$ It was found that ammoniacal water $(2.8 \%)$, sodium thiosulfate $\left(10^{-3}\right.$ $\mathrm{mol} / \mathrm{litre})$, and 1.2-Cyclohexanedione dioxime $\left(10^{-4}\right.$ $\mathrm{mol} / \mathrm{litre}$ ) could be used as an efficient antifogging agent. 


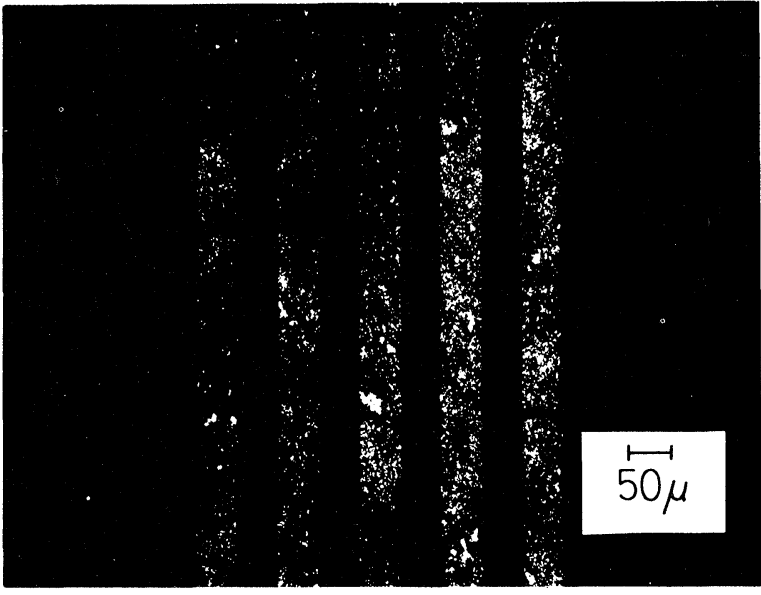

FIGURE 3 Fine line patterns obtained (line width: $50 \mu \mathrm{m}$; line interval: $50 \mu \mathrm{m}$ ).

The nuclei produced by exposure were developed by electroless copper plating solution at $60^{\circ} \mathrm{C}$, comprising copper sulfate, EDTA, paraformaldehyde, potassium cyanide, dipyridyl and wetting agent, without employing ary activating pretreatment.

In $15 \sim 20$ minutes, resolution patterns $1 \sim 2 \mu \mathrm{m}$ in thickness were formed (Figure 3). From this figure, it is observed that fine patterns $(50 \mu \mathrm{m}$ line width and 50 $\mu \mathrm{m}$ line interval) can be obtained by metal particles deposition. In $10 \sim 15$ hours, a copper circuit pattern $30 \sim 35 \mu \mathrm{m}$ in thickness was formed. Figure 4 shows the PCB experimentally produced using this method. This method makes it possible to fabricate a PCB with $2.5 \mathrm{~kg} / \mathrm{cm}$ adhesive strength and 40 second $\left(260^{\circ} \mathrm{C}\right)$ solder float resistance.

\section{CONCLUSION}

It has been shown that printed circuit patterns can be formed on an insulating substrates utilizing AQS-metal salts photochemical reaction. $\mathrm{PdCl}_{2}-\mathrm{AQS}-$ Glycerin

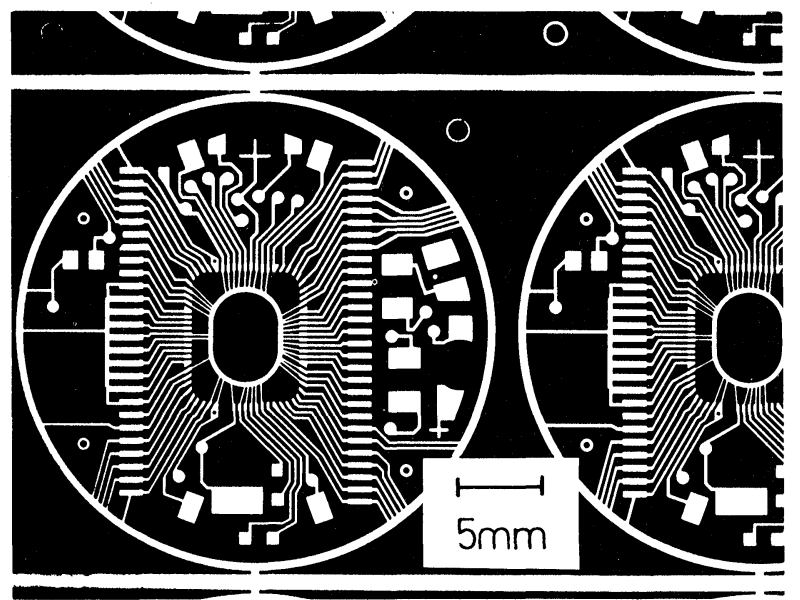

FIGURE 4 Experimentally produced printed circuit board.

system photographic sensitivity is relatively high. In the fixing process, ammonia water, sodium thiosulfate and 1.2 cyclohexanedione dioxime can be used as an antifogging agent. This is a simple process to fabricate a PCB with fine patterns and good adhesion.

At present, basic studies on the process steps are being carried out and will be reported on in detail in the future.

\section{REFERENCES}

1. D. J. Sharp, U.S. Pat. 3,562,005 (1971).

2. H. Jonker et al., U.S. Pat. 3,674,485 (1972).

3. J. Polichette and E. J. Leech, U.S. Pat. 3772078 (1973)

4. H. Tabei et al., J. Electrochem. Soc., 121, 67 (1974).

5. J. L. Bolland and H. R. Cooper, Nature, 172, 413 (1953); Proc. Roy. Soc., A225, 405 (1954)

6. C. F. Wells, Trans. Farad. Soc., 57, 1703, 1719 (1961).

7. A. Schoen, U.S. Pat. 2,504,593 (1950).

8. J. Kosar, Light-Sensitive Systems, J. Wiley \& Sons, Inc., New York, (1965), p. 272.

9. H. Jonker et al., Phot. Sci. Eng., 13, 1 (1969).

10. J. J. Kelly et al., J. Electrochem. Soc., 122(8), 1104 (1975). 

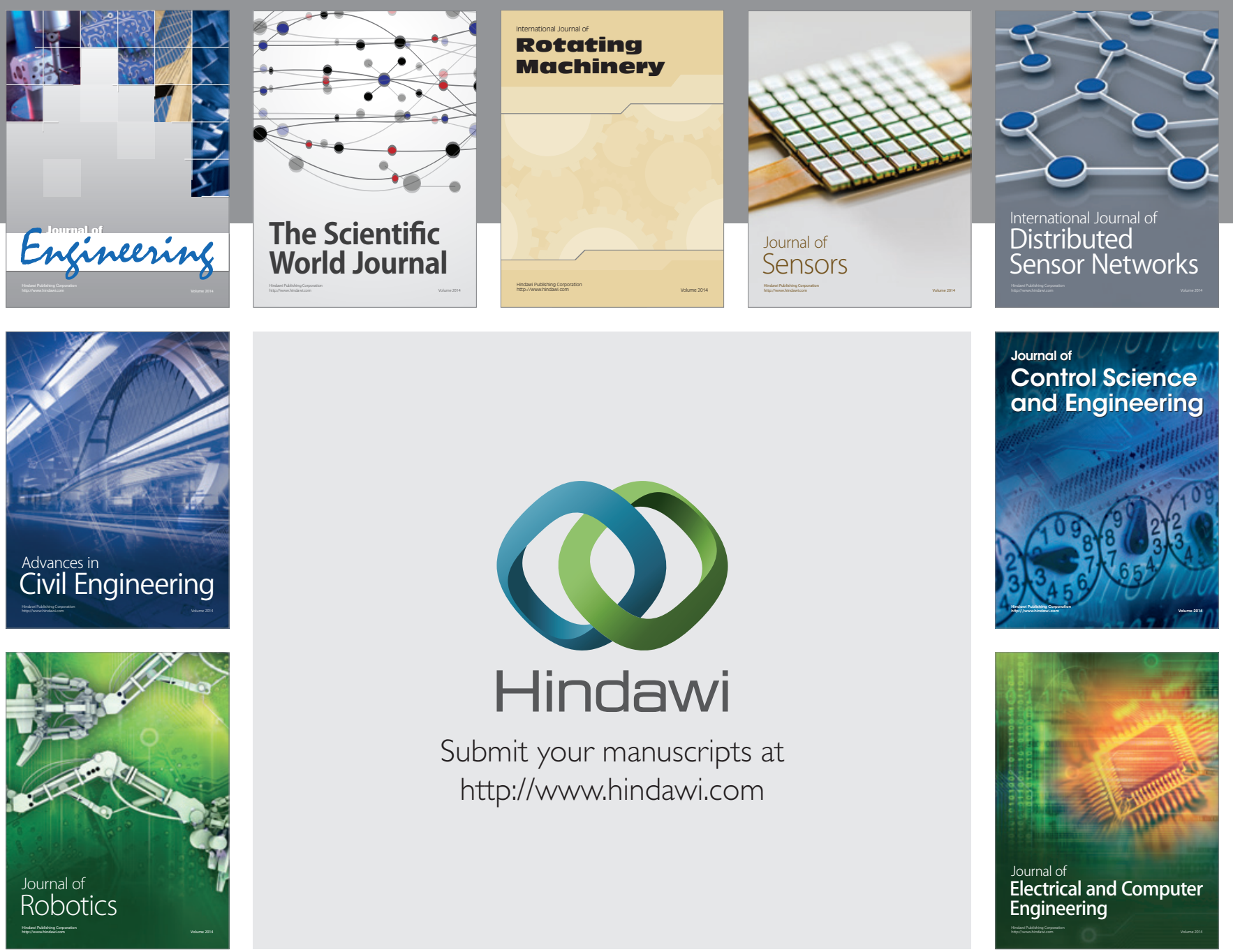

Submit your manuscripts at

http://www.hindawi.com
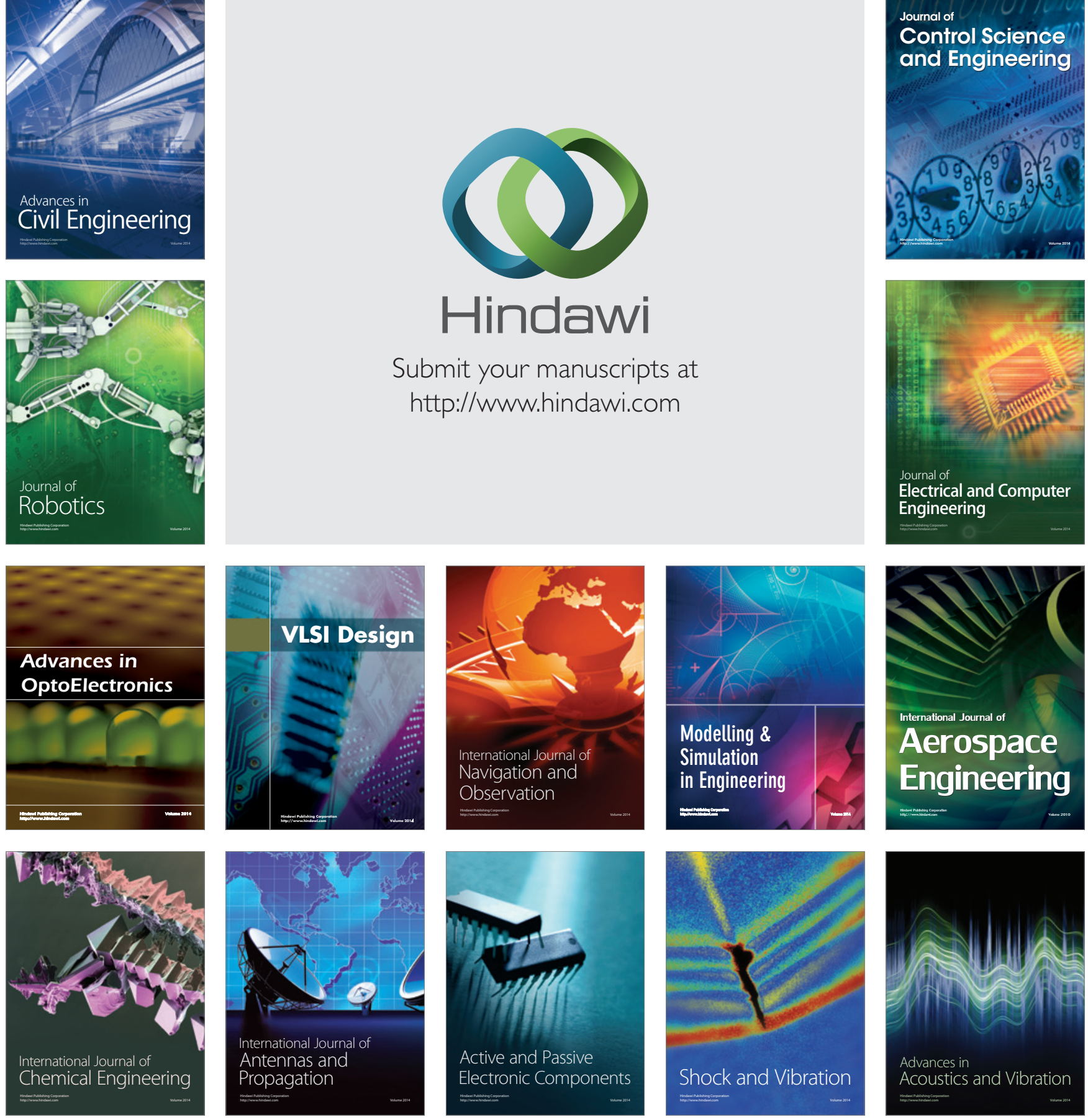